\title{
Prioritising Facilities Management Services for Benchmarking in Selected Cities in Nigeria
}

\author{
"Yewande Adewunmi, Modupe Omirin and Hikmot Koleoso
}

Published online: 31 July 2016

To cite this article: Yewande Adewunmi, Modupe Omirin and Hikmot Koleoso. (2016). Prioritising facilities management services for benchmarking in selected cities in Nigeria. Journal of Construction in Developing Countries, 21 (1): 131-145. doi: $10.21315 / \mathrm{jcdc} 2016.21 .1 .7$

To link to this article: http://dx.doi.org/10.21315/jcdc2016.21.1.7

Abstract: Due to the high cost of benchmarking, it is often difficult to provide required resources for it. Therefore, to benchmark successfully, it is often necessary to identify services that are most important for the efficiency of the organisation and prioritise them. This paper examines the facilities management (FM) services that are most in need of benchmarking in Nigeria. Data were collected through self-administered questionnaires that were sent to 120 facilities management organisations in Lagos metropolis, 50 in Abuja and 15 in Port Harcourt. The survey achieved a total response rate of $76 \%$ in Lagos, $58 \%$ in Abuja and $87 \%$ in Port Harcourt respectively. The five services that need benchmarking the most were found to be: utilities, maintenance, security, cleaning and waste disposal, property management and Information Technology in that order. Also, repeated measures analysis of variance results showed that the differences indicated in the respondents' rating of how important it is to benchmark these FM services is statistically significant. Kruskal Wallis test showed that there was difference in the importance of FM services for benchmarking based on professional affiliation of the FM. The study provided information on how to prioritise these services for benchmarking in order to conserve resources of Nigerian organisations.

Keywords: Benchmarking, Facilities management services, Nigeria

\section{INTRODUCTION}

Facilities management (FM) has the potential to improve processes by which workplaces can be managed, thereby inspiring people to give their best and contribute positively to economic growth and organisational success (Alexander, 2003). Economic crisis and global advancement in information technology have changed the way businesses of today operate. These have allowed for more cost effectiveness and enhanced prospects for breakthrough improvements within short periods of time.

Benchmarking is a continuous, systematic process which enhances effectiveness of organisations by evaluating products, services or work processes against recognised best practices (Spendolini, 1992). Benchmarking examine processes, as it is recognised that organisations achieve superior results only through a proper understanding of how inputs are transformed into outputs (Hinton, Francis and Holloway, 2000). Therefore, the development of a benchmarking culture is based on the desire to change processes (Magd and Curry, 2003). According to the International Facility Management Association,

The School of Construction Economics and Management (Property Studies), University of the Witwatersrand, Johannesburg, SOUTH AFRICA

*Corresponding author: yewande.adewunmi@wits.ac.za

(C) Penerbit Universiti Sains Malaysia, 2016 
benchmarking is one of the key competences of a facilities manager, particularly as it relates to the aspect of quality assessment and innovation (Wong, 2005). Facilities management benchmarking affords companies the opportunity to constantly compare their own performance against that of others. This provides them with an external focus and the prospect of achieving best practices. According to Williams (2003), facilities expenditure takes up to $15 \%$ of an organisation's yearly budget; benchmarking can help justify this huge investment thus improving the recognition given to facilities within organisations.

It is usually difficult to provide the required resources for benchmarking, even in countries where it is widely applied (Garengo et al., 2005). In spite of the identified advantages, benchmarking is less widely accepted in Nigeria (Adewunmi, Omirin and Koleoso, 2013). This limits its application hence making it necessary to benchmark only those services that are most important for the efficiency of organisations. Aspects of benchmarking including identification of FM services to prioritise for benchmarking, as enunciated earlier, has been subjects of discussion by both academics and practitioners for over 15 years mainly in the UK, USA, Europe, Asia and Australia (Varcoe, 1996; Massheder and Finch, 1998a; Massheder and Finch, 1998b; Ho et al., 2000; Stoy, 2007; Lai and Yik, 2008; Madritsch, 2009; Roka-Madarasz, 2010; Bailey and Mc Lennan, 2010). However there are limited studies that address these issues within the context of developing countries such as Nigeria.

The paper therefore examined the FM services that are in need of benchmarking the most in the Nigerian context in other to guide the prioritising process. Two hypotheses were postulated to guide this research. The first determines if the differences indicated by respondents in the rating of how important it is to benchmark the different FM services is statistically significant. The second determines whether there is a significant difference in these ratings based on location and professional affiliation of the respondents.

The remaining part of this paper is arranged in the following manner. First part is a review of literature on meaning and types of benchmarking, scope of FM and the concept of the FM services that should be benchmarked. The second part of the paper discusses the research method for empirical examination of FM services that need benchmarking the most. In the third part of this paper, we present analysis of data and presentation of results while the final section contains the concluding remarks.

\section{LITERATURE REVIEW}

\section{What is Benchmarking?}

Benchmarking is a continuous analysis of strategies, functions, processes, performances, products or services, etc. It involves comparison within or between best-in-class organisations and commences with obtaining information through appropriate data collection method, with the intention of assessing an organisation's current standards and implementing self-improvement to scale or exceed those standards. (Anand and Kodali, 2008: 259).

Studies in the past were more focused on organisational pre-requisites and criteria for successful benchmarking, which include: 
1. Focus around customers, employees and continuous improvement.

2. Strategic focus and flexibility, management support, openness to change, willingness to share information, etc.

3. Need for good communication across the organisation, process understanding and commitment.

Currently, the focus of benchmarking literature has shifted and addresses issues on improving the benchmarking process, i.e. it focuses on in-depth study of the benchmarking process to identify the missing links. One thing that is increasingly evident is that, benchmarking should occur at the input, process stage, where lead benchmarks of performance are identified. Hence, benchmarking must evolve use of backward looking static measures to more forward looking dynamic ratios.

\section{Types of Benchmarking}

According to Camp (1989), Watson (1993), Massheder and Finch (1998a), Kyro (2003), Jaques and Povey (2007), Magd (2008) and Moriarty and Smallman (2009), the three basic types of benchmarking are:

1. internal benchmarking,

2. competitive benchmarking and

3. generic (functional) benchmarking (Spendolini, 1992).

They are reviewed as follows:

1. Internal benchmarking focuses on similar activities within the organisation but in different departments or at different locations.

2. Competitive benchmarking focuses on direct competitors preferably with the same customer base. The disadvantages are that data may be difficult to collect, although this can be overcomed if the competitors enter into the process on the basis that it is of mutual advantage.

3. Functional benchmarking compares with organisations that are recognised as leaders in their particular field even where that field differs from that of the company being benchmarked.

The three types of benchmarking as identified above are equally applicable to facilities management. However, in view of the discipline's strategic role in supporting the core business of any organisation, three further types of benchmarking may be used (Massheder and Finch, 1998a; Kyro, 2003; Moriarty and Smallman, 2009) which are strategic, process and generic benchmarking.

Strategic benchmarking is carried out at a level where there is a need to compare/contrast the strategic mission and direction of the organisation. The procedure looks at all manner of broad ranging issues that have an influence on the organisation's strategy. These can include non-process issues such as people and culture, and possibly the availability of facilities.

Process benchmarking looks specifically at the methods, procedures and business processes of world-class companies, regardless of the core business of the company i.e. the companies being benchmarked do not have to be in the same 
line of business let alone competitors. The skill in making this type of benchmarking a success is the identification of common metrics and processes.

Finally there is generic benchmarking, which constitutes the broadest application of data collection. It has no defined parameters. It is confined only by the understanding of how to translate the data obtained and how to put it to use.

\section{Scope of FM}

According to Atkin and Brooks (2000), FM can cover a wide range of services including real estate management, financial management, change management, human resources management, health and safety and contract management. In addition, there is building management, domestic services (such as cleaning and security) and utilities supplies. These last three responsibilities are the most visible, while others are subtler, though of no less importance. According to Kincaid (1994), FM emerged through the integration of three main strands of activity: property management (real estate), property operations and maintenance and office administration.

FM is wide and covers in its scope the provision of many varied services (Barrett, 1995; Noor and Pitt, 2009). It is wider than building operations and maintenance (Best et al. [2003] cited in Chitopanich [2004]) and its scope has been captured in varied ways. FM encompasses workplace, facility, support services, property, corporate real estate, and infrastructure (Chitopanich, 2004). The scope of FM has been captured in varied ways (Amaratunga, Baldry and Sarshar, 2000; Chung, 2008; Noor and Pitt, 2009; Waheed and Fernie, 2009; Lindkvist and Elmualim, 2010; Halim et al., 2011; Drion, Melissen and Wood, 2012). Then (1999) identified the scope of FM to cover: strategic facilities planning, strategic asset management, asset maintenance management and facilities service management.

In general, support services concerning FM range from building operational services to construction management and real estate services (Chitopanich, 2004). The author provided a diversified-scope-of-FM services, which comprises nine groups and 61 services.

FM broadly covers building related and service related functions also known as hard and soft FM. The new European FM standard expresses that the field of FM can be grouped around client demands, which can be summarised under two main headings: the first being Space and Infrastructure and the second being People and Organisation (Jensen, 2008).

The scope of FM should include all three levels of the decision pyramid of the FM organisation i.e. strategic, tactical and operational levels

The strategic level is concerned with the long-range aim and direction of the FM functions. This includes setting objectives in response to the purpose of the FM functions and carrying out long-term planning, taking the external requirements into consideration. The strategic level has responsibility for result and profitability. The work is carried out for example through planning, modeling and simulation. Strategic FM means that FM extends beyond operational matters to include strategic considerations for the future facility and service provision. For FM to be effective it is important that there is strategic integration within the organisation (Featherstone and Baldry, 2000; Noor and Pitt, 2009) and this can be 
done by demonstrating its potential relevance to the overall business process (Hinks and Hanson, 1998).

The tactical (managerial) level is concerned with making the FM organisation function in totality. It includes identifying needs and defining goals that meet these needs. The tactical work includes for instance controlling, analysing, programming and budgeting, often on a yearly basis. It incorporates defining routines and methods, setting standards, drawing up schedules and securing resources.

The operational level is concerned with the day-to-day decisions in operating facilities. This level is not different in most organisations. Barrett (1995) has identified that in several of the organisations, FM is considered to be a purely operational function and hence, facilities departments exist to provide day-to-day service, not to consider how facilities could benefit the core business in the long run. According to Barrett (2000) Benchmarking of facilities falls under operational FM and is needed to provide technically sound, responsive services.

\section{FM Practice in Nigeria}

Facilities management was introduced into Nigeria through globalisation, as a result of the changes that happened as part of relocation activities of oil and gas multinational companies (Ojo, 2002). Some organisations in Nigeria often assign the management of their capital assets to an administrative officer or finance officer who advises on property decisions, supervises operations and maintenance activities, budgets and hires other professionals. Today government agencies, corporations, profit and non-profit institutions have realised that managing these functions within traditional organisational structures are unsatisfactory. Facilities management has thus emerged to overcome the fragmented management of facilities.

In Nigeria, most FM practitioners come from different professional backgrounds with little or no specialist competences. Fortunately, the global FM professional body IFMA, which offers guidance and expertise to members has now been established In the country. IFMA Nigeria organises training options for qualifications as professional facility manager and certified facility manager to its members who will like to take the professional qualification route. In addition, the University of Lagos and Ahmadu Bello University, Zaria offers masters courses in FM for those that want to pursue the academic qualification route (Adewunmi, Ajayi and Ogunba, 2009). Although yet to find wide applications in Nigeria, FM has been adopted in both private and public sectors of the the country's economy.

\section{The Concept of the Processes for FM Benchmarking}

A look at services for benchmarking helps in identifying what to benchmark. The nature and effectiveness of benchmarking is based on what you benchmark and against whom, i.e. the benchmarking activities. Benchmarking was concerned with comparing measures of business or product performance, but it has been extended to business processes (Cassell, Nadin and Gray, 2001). Determining what to benchmark is in itself a key issue. Adam and Van de Water (1995: 25) suggested that a number of questions should be used to aid this decision as follows: 
1. What are the critical success factors for our organisation (e.g. time to market, customer involvement, innovation, etc.)?

2. Which processes are causing the most trouble?

3. Which processes contribute most to customer satisfaction and which are not performing up to expectations?

4. What are the competitive pressures impacting the organisation the most (e.g. low prices, flexibility, terms of sale, product performance etc.)?

5. Which processes or functions have the greatest potential for differentiating our organisation from the competition?

This study covers services under the scope of FM as indicated by authors such as Williams (2003), Wauters (2005) and Kok, Mobach and Omta (2011) and includes: property, maintenance, alterations and fitting out, cleaning and waste disposal, security, utilities, archiving, reprographics and stationery, distribution, travel, catering, space use and IT equipment. The facilities processes with greatest potentials in differentiating the organisation is the focus of this study because the use of performance evaluation tools is constrained by insufficient resources, poor infrastructure and relative infancy of the FM practice, hence the need to adapt to those issues (Koleoso et al., 2013)

The nature and application of the wide range of benchmarking activities consist of data, process, functional and strategic benchmarking. The critical success characteristic of all types of benchmarking is the examination of processes, as it is only through a proper understanding of how inputs are transformed into outputs that organisations can achieve superior results (Hinton, Francis and Holloway, 2000). Therefore, the development of a benchmarking culture is based on willingness of organisations to search for ideas outside the organisation (Magd and Curry, 2003) and the desire to change processes as well as outputs.

Many companies in their attempt to benchmark devote little or no attention to alignment of their practices with market demands and strategic objectives. This is common with small and medium sized companies where strategic knowledge is low (Carpinetti and Melo, 2002).

Previous studies such as Williams (2000) and Kok, Mobach and Omta (2011) focused on areas of FM that need benchmarking in developed countries but not in developing countries. Furthermore, these studies were not empirical and did not examine whether the prioritising of FM services for benchmarking is based on an organisation's location. This study will address all these gaps in the discussion.

\section{RESEARCH METHODS}

The data used in the study were collected on variables of the same sample at one point in time (cross-sectional survey). Findings from literature review and interviews with two facilities managers were used for the design of the self-administered questionnaire that was developed for the study. These questionnaires were validated by two facilities managers, two senior academic researchers and later through a pilot study, the questionnaire was again refined using new set of information that became available from involvement in the calibration of benchmarking software, "the estates master" to the Nigerian environment, at 
International Facilities and Property Information Centre, United Kingdom. Thereafter, it was again pre-tested. Self-administered questionnaire was the chosen instrument of study because it has been known to give higher response rates for studies in the built environment in Nigeria (Olaleye, 2000).

The sample frame for FM organisations in Lagos, Abuja and Port Harcourt as obtained from the International Facility Management Association list is 237 organisations, made up of 172 in Lagos, 50 in Abuja and 15 in Port Harcourt respectively. IFMA is the professional body that offers guidance and training to facilities managers in Nigeria, many of the established facilities managers are registered with this body. Questionnaires were administered on 120 facilities management organisations in Lagos metropolis, 50 in Abuja and 15 in Port Harcourt. This sample size was determined using sample table adapted from Bartlett, Kotrlik and Higgins (2001). In Lagos, 91 questionnaires were retrieved, in Abuja, 29 and Port Harcourt, 13 were retrieved. Hence the survey achieved a total response rate of $76 \%$ in Lagos, $58 \%$ in Abuja and $87 \%$ in Port Harcourt respectively. In order to minimise bias, the responding organisations in Lagos were chosen using simple random sampling method, while the total population were included in the sample in Abuja and Port Harcourt due to their small numbers.

Lagos in the South West is an ideal study area because it is the business nerve centre of Nigeria, which houses several of Nigeria's large corporations that require facilities management services. Abuja in the north, the nation's capital with its premier state of infrastructure has ever growing need for commercial and residential real estates. Port Harcourt in the South East is Nigeria's oil and gas business hub and houses the head offices of many oil and gas and related companies. However, it is recognised that the outcome of this study would not necessarily apply, in absolute terms, to all corporations throughout the country. This is because the property market is highly localised in nature and no urban area can be representative of all cities in the country since there will be different cultural, social and institutional settings.

The first section of the questionnaire includes variables such as company characteristics of the respondents including size, geographical coverage, size of buildings managed, and FM training undertaken by staff of the FM department. The second section focused on identifying the FM services that should be prioritised for benchmarking. The services are listed in Table 1. The reliability of scale for the questions was tested using Cronbach's Alpha method which was found to be 0.897 (89.7\%). This result suggested that the instrument of evaluation (questionnaire) is highly reliable and that there is an internal consistency of the items included in it. This is judging from the fact that the reliability figure obtained is substantially higher than the 0.7 value $(89.7 \%>70 \%)$ required in statistical analysis (Field, 2009).

The data was analysed with the aid of Statistical Package for Social Science (SPSS). Relative importance index (RII) was used to determine the relative importance of the services (Adewunmi, Ajayi and Ogunba, 2009) while repeated measures analysis of variance was used to test linear trends in FM processes studied (Hackett and Parmanto, 2005). 
Table 1. Characteristics of the Respondents' Organisations

\begin{tabular}{|c|c|c|c|c|c|c|c|c|}
\hline $\begin{array}{l}\text { Company } \\
\text { Size }\end{array}$ & Freq. & $\%$ & $\begin{array}{l}\text { Company } \\
\text { Space }\end{array}$ & Freq. & $\%$ & $\begin{array}{l}\text { Academic/ } \\
\text { Professional } \\
\text { Qualifications }\end{array}$ & Freq. & $\%$ \\
\hline $0-50$ & 41 & 31.3 & $\begin{array}{l}\text { Less than } \\
100,000 \text { sqm }\end{array}$ & 34 & 28.6 & $\begin{array}{l}\text { MSc/MA } \\
\text { facilities } \\
\text { management }\end{array}$ & 29 & 30.5 \\
\hline $51-100$ & 15 & 11.5 & $\begin{array}{l}100,000-250,000 \\
\text { sqm }\end{array}$ & 44 & 37 & CFM & 12 & 12.6 \\
\hline $101-250$ & 22 & 16.8 & $\begin{array}{l}250,000-500,000 \\
\text { sqm }\end{array}$ & 16 & 13.4 & FMP & 15 & 15.7 \\
\hline $251-500$ & 8 & 6.1 & $\begin{array}{l}500,001-750,000 \\
\text { sqm }\end{array}$ & 13 & 10.9 & $\begin{array}{l}\text { Undergraduate } \\
\text { modules in FM }\end{array}$ & 17 & 17.9 \\
\hline $501-100$ & 15 & 11.5 & $\begin{array}{l}1,000,000 \text { sqm } \\
\text { and above }\end{array}$ & 12 & 10.1 & Others & 22 & 23.3 \\
\hline Over 1000 & 30 & 22.8 & & & & & & \\
\hline Total & 131 & 100 & Total & 119 & 100 & Total & 95 & 100 \\
\hline
\end{tabular}

\section{PRESENTATION AND DISCUSSION OF RESULTS}

\section{Characteristics of the Respondents' Organisations}

The companies in this study were in three categories as follows: Small companies, which have employee size of 50 and under, medium sized with between 51-250 employees and large companies with above 250 employees (see Table 1). The study found that, 41 (31.3\%) of the companies surveyed were small companies, another 37 (28.3\%) were medium sized while 53 (40.4\%) were large companies. Majority of these organisations are therefore small and medium sized companies. It was indicated that $49.2 \%$ of the organisations operate in and outside Nigeria. Most of the organisations surveyed $(44=37 \%$ ) had a floor space of between 100,000 and 250,000 square metres. Respondents with only facility management professional (FMP) qualification were 15 (15.7\%), another 17 (17.9\%) possessed a first degree in FM, 12 (12.6\%) had only certified facility manager (CFM), while few five $(5.3 \%)$ possessed other qualifications in FM (see Table 1).

\section{Relative Importance of FM Services That Require Benchmarking}

For the purpose of analysis 13 variables under FM premises and services that were obtained from literature and streamlined from the pilot study were measured in this work. There is need to prioritise services that require benchmarking to conserve resources of the organisation since benchmarking can be costly and resources consuming especially for small and medium scale organisations (Garengo et al., 2005). Therefore, the purpose of the analysis here is to identify FM services that need benchmarking the most in the Nigerian context so that they can be given priority. Identifying what to benchmark is a requirement at the planning stage of 
benchmarking (Huq, Abbo and Huq, 2008). The services were measured on a 5 point interval scale ( $1=$ Not important, $5=$ Very important $)$.

Table 2 showed that for the three locations, the five top ranked services were utilities $(R \|=0.854)$, maintenance $(R \|=0.851)$, security $(R \|=0.802)$, cleaning and waste disposal $(\mathrm{RII}=0.794)$ and accommodation $(\mathrm{R} \|=0.778)$ in that order. The least five ranked were catering $(\mathrm{R} \|=0.505)$, travel $(\mathrm{R} \|=0.528)$, reprographics $(\mathrm{R} \|=$ $0.580)$, distribution $(\mathrm{RII}=0.621)$ and archiving $(\mathrm{R} \|=0.645)$.

Table 2. FM Services for Benchmarking

\begin{tabular}{|c|c|c|c|c|c|c|c|c|}
\hline \multirow[t]{2}{*}{ Rate services } & \multicolumn{2}{|c|}{ Lagos } & \multicolumn{2}{|c|}{ Abuja } & \multicolumn{2}{|c|}{ PH } & \multicolumn{2}{|c|}{ Aggregate } \\
\hline & RII & Rank & RII & Rank & RII & Rank & RII & Rank \\
\hline Utilities & 0.892 & 2nd & 0.710 & 2nd & 0.908 & 2nd & 0.854 & 1st \\
\hline Maintenance & 0.899 & 1st & 0.717 & 1st & 0.815 & 4 th & 0.851 & 2nd \\
\hline Security & 0.820 & 4 th & 0.710 & 2nd & 0.877 & $3 r d$ & 0.802 & $3 r d$ \\
\hline $\begin{array}{l}\text { Cleaning and } \\
\text { waste disposal }\end{array}$ & 0.848 & $3 r d$ & 0.676 & $3 r d$ & 0.677 & 6th & 0.794 & 4 th \\
\hline $\begin{array}{l}\text { Property/ } \\
\text { accommodation }\end{array}$ & 0.791 & 5 th & 0.662 & 4 th & 0.938 & lst & 0.778 & 5 th \\
\hline IT equipment & 0.785 & 6th & 0.641 & 5 th & 0.723 & 5 th & 0.747 & 6th \\
\hline $\begin{array}{l}\text { Alterations and } \\
\text { fitting out }\end{array}$ & 0.752 & 7th & 0.586 & 7th & 0.723 & 5 th & 0.713 & 7 th \\
\hline Space use & 0.752 & 7th & 0.593 & 6th & 0.569 & 8th & 0.699 & 8th \\
\hline $\begin{array}{l}\text { Archiving or } \\
\text { storage }\end{array}$ & 0.697 & 8th & 0.503 & 9th & 0.6 & 7 th & 0.645 & 9th \\
\hline Distribution & 0.675 & 9th & 0.510 & 8th & 0.492 & 9th & 0.621 & 10th \\
\hline Reprographics & 0.635 & 10th & 0.497 & 10th & 0.385 & 10th & 0.580 & 11 th \\
\hline Travel & 0.567 & 11 th & 0.421 & 12 th & 0.492 & 9th & 0.528 & 12 th \\
\hline Catering & 0.532 & 12 th & 0.441 & 11 th & 0.462 & 9th & 0.505 & 13th \\
\hline
\end{tabular}

In Lagos, the five top ranked services were maintenance (RII $=0.899)$, utilities (RII =0.892), cleaning and waste disposal (RII =0.848), security (RII =0.82), and property $(R \|=0.791)$. The least five ranked were catering ( $R \|=0.532)$, travel $(R \|=0.567)$, reprographics $(R \|=0.635)$, distribution $(R \|=0.675)$ and archiving $(R \|=$ 0.697).

In Abuja, the five top ranked services were Maintenance (R\|l $=0.717)$, utilities $(R I I=0.710)$, security $(R \|=0.710)$, cleaning and waste disposal $(R I I=0.676)$ and property $(\mathrm{R} \|=0.662)$. The least ranked were catering $(\mathrm{R} \|=0.441)$, reprographics $(\mathrm{R} I \mathrm{=}=0.497)$, archiving $(\mathrm{RII}=0.503)$ and distribution $(\mathrm{RII}=0.510)$.

In Port-Harcourt, the five top ranked services were Property $(\mathrm{RII}=0.938)$, utilities (RII $=0.908)$, security $(\mathrm{RII}=0.877)$, maintenance $(\mathrm{RII}=0.815)$ and $\mathrm{IT}$ equipment (RII $=0.723)$. The least ranked were reprographics (RII $=0.385$ ), distribution, travel and catering (with $R \|=0.492$ each), space use $(R \|=0.569)$, cleaning and waste disposal $(R \|=0.677)$ and archiving $(R \|=0.6)$. 
A study by Koleoso, Adewunmi and Adejumo (2012) showed that services such as cleaning and waste disposal, maintenance, security and operation of utilities are frequently provided within the Nigerian FM practice. Specialised services such as reprographics, catering and travel services were among the least performed tasks. This could be part of the reasons why respondents in this study did not indicate these specialised services for benchmarking.

A close look at the rankings/results of this study showed that FM services were similarly ranked across the three locations. Maintenance, property utilities and securities were common themes in the highly ranked services for benchmarking. This is not misplaced because maintenance budget is a main concern for most organisations and it takes about $15 \%$ of the organisation's expenditure (Williams, 2003). Quite a bulk of maintenance budget goes into the purchase of diesel for the running of generators used to power buildings, which are relied on heavily due to incessant power cuts from the national power generation and distribution company i.e. Power Holding Corporation of Nigeria (PHCN). Also, security concerns are becoming increasingly crucial in the major cities that were featured in this study, especially with recent bombings of public and major facilities by the infamous religious sect Boko Haram. In Port-Harcourt and other major cities in Southern Nigeria especially the oil producing areas, expatriates and public figures have been kidnapped. Although Niger Delta unrest is decreasing in recent times because of the amnesty programme put together by the Federal Government to serve as a mediator between government and militants, grant amnesty, assist with disarmament as well as rehabilitation of militants (Ejovi and Ebie, 2013). There is still need to prevent further insurgency by investing in security. This is against the back drop that the general public are aware that the services of the Nigerian police in keeping law and order are grossly inefficient. All these incidents boil down to lack of adequate infrastructure within the country and terrorist threats.

Table 3. Repeated Measures Analysis of Variance for Significant Difference in the Services for Benchmarking in FM

\begin{tabular}{|c|c|c|c|c|c|c|c|}
\hline \multicolumn{8}{|c|}{ Multivariate Tests ${ }^{1}$} \\
\hline Effect & & Value & $\mathbf{F}$ & Hypothesis df & Error df & Sig. & $\begin{array}{l}\text { Partial Eta } \\
\text { Squared }\end{array}$ \\
\hline \multirow[t]{4}{*}{ Processes } & Pillai's Trace & .730 & $22.249^{2}$ & 12.000 & 99.000 & .000 & .730 \\
\hline & Wilks' Lambda & .270 & 22.2492 & 12.000 & 99.000 & .000 & .730 \\
\hline & Hotelling's Trace & 2.697 & 22.2492 & 12.000 & 99.000 & .000 & .730 \\
\hline & $\begin{array}{l}\text { Roy's Largest } \\
\text { Root }\end{array}$ & 2.697 & 22.2492 & 12.000 & 99.000 & .000 & .730 \\
\hline
\end{tabular}

Notes:

1. Design: Intercept, within subjects design: services 2. Exact statistic 


\section{Hypothesis Testing}

The hypothesis that "there is no significant difference in the priority to be accorded to these services for benchmarking" was postulated to confirm if the ranking of the FM services by Nigerian FM practitioners as found in Table 2 is statistically true.

The Wilks' Lambda Value of $0.270 ; F_{(12,99) ;} p=0.000$ at $99 \%$ confidence level in which the study was conducted revealed that the difference indicated by respondents' rating of the priority to be accorded to the benchmarking of the FM services is statistically significant (see Table 3 ). Therefore the results of the null hypothesis was rejected.

In addition the second hypothesis testing using Kruskal Wallis test revealed that there was no significant difference in the rating of the importance of FM services based on location while further reveals that the difference in ranking presented in Table 2 across the three cities is real and not as a result of random variation. On the other hand there was significant difference based on the professional affiliation of the respondents (see Table 4) showing that there is a link between ranking of FM services and professional affiliations in FM. Professional affiliations of the respondents influences ranking the importance of FM services.

Table 4. Kruskall Wallis Test to Test for Significant Difference in Ranking of FM

Services Based on Location and Professional Affiliations of Respondents

\begin{tabular}{llll}
\hline Location & \multicolumn{3}{c}{ Professional Affiliations } \\
\hline Chi-square & .821 & Chi-square & 24.197 \\
df & 2 & df & 11 \\
Asymp. sig. & .663 & Asymp. sig. & .012 \\
\hline
\end{tabular}

\section{CONCLUSION}

The results of the study showed that in Nigeria benchmarking is most important to the following services: utilities, maintenance, security and cleaning/waste disposal, IT equipment in that order. The results of the repeated measures analysis of variance showed that the difference indicated by respondents' rating of the FM services that benchmarking is important for is statistically significant. There was difference in the ranking of FM services for benchmarking based on professional affiliation in FM.

The ranking shows the services that the facilities manager should prioritise to enable cost effective benchmarking and to achieve the required conservation of resources. It also shows service areas were the facilities manager can reduce unnecessary expenditure through benchmarking thereby improving the profit of organisations without compromising on the quality of services delivered. Benchmarking itself is useful for cost reduction, process improvement, standardisation of FM practices as well as helping to justify investment in facilities by organisations .

In many organisations globally there have been increasing needs for FM services to help maximise productivity. It also helps organisations respond efficiently and economically to present and future demands. The ranking of the 
services by FM organisations cannot be isolated from the need to respond to lack of adequate infrastructure within the country and insecurity threats, including terrorism. Competency in benchmarking helps the facilities manager to respond to these changes.

The Nigerian Government needs to create an enabling environment for FM through provision of adequate infrastructure. In addition, benchmarking tools should be designed in such a way that will make benchmarking of these priority services affordable to practitioners. IFMA and research institutions should focus their sensitisation efforts, research and data gathering exercises on these priority areas to further develop benchmarking.

This paper is part of a PhD study on benchmarking practice in FM in Nigeria and will serve as a guide to those that will conduct research in this area in future. Future studies could assess from the perspective of the customers. They could also focus on the importance of the different stages in the benchmarking process or on a particular sector. Also further studies can be extended to other countries in the developing world.

\section{ACKNOWLEDGEMENT}

An earlier version of this study was presented at the 2014 Chartered Institute of Building World 107 Conference held in Lagos, Nigeria, between 28-30 January 2014 and published in the proceedings of the conference.

\section{REFERENCES}

Adam, P. and Van de Water, R. (1995). Benchmarking and the bottom line: Translating business re-engineering into bottom-line results. Industrial Engineering, 27(2): 24.

Adewunmi, Y.A., Ajayi, C. and Ogunba, O. (2009). Facilities management: Factors influencing the role of Nigerian estate surveyors. Journal of Facilities Management, 7(3): 246-258. doi: 10.1108/14725960910971504.

Adewunmi, Y.A., Omirin M.M. and Koleoso, H. (2013). Use of benchmarking in facilities management in Nigeria. Proceedings of the International Postgraduate Research Conference. Manchester, UK: University of Salford, 681-693.

Alexander, K. (2003). A strategy for facilities management. Facilities, $21(11 / 12)$ : 269-274. doi: 10.1108/02632770310500338.

Amaratunga, D., Baldry, D. and Sarshar, M. (2000). Assessment of facilities management performance: What next. Facilities, 18(1/2): 66-75. doi: $10.1108 / 02632770010312187$.

Anand, G. and Kodali, R. (2008). Benchmarking the benchmarking models. Benchmarking: An International Journal, 15(3): 257-291. doi: $10.1108 / 14635770810876593$.

Atkin, B. and Brooks, A. (2000). Total Facilities Management. Oxford: Blackwell Science.

142/PENERBIT UNIVERSITI SAINS MALAYSIA 
Bailey, T.J. and Mc Lennan, P.S. (2010). Performance assessment: It's role in managing facilities services. Paper presented at the Euro Facility Management Conference. Madrid, Spain, 1-2 June.

Barrett, P. (2000). Achieving strategic facilities management through strong relationships. Facilities, 18(10-12): 421-426. doi: 10.1108/02632770010349655. . (1995). Facilities Management: Towards Better Practice. Oxford: Blackwell Science.

Bartlett, J.E., Kotrlik, J.W. and Higgins, C.C. (2001). Organizational research: Determining appropriate sample size in survey research. Information Technology, Learning and Performance Journal, 19(1): 43-50.

Camp, R. (1989). Benchmarking: The Search for Industry Best Practice that Leads to Superior Performance. Wisconsin, US: ASQC Quality Press.

Carpinetti, L. and Melo, A. (2002). What to benchmark?: A systematic approach and cases. Benchmarking: An International Journal, 9(3): 244-255. doi: $10.1108 / 14635770210429009$.

Cassell, C., Nadin, S. and Gray, M.O. (2001). The use and effectiveness of benchmarking in SMEs. Benchmarking: An International Journal, 8(3): 212222. doi: 10.1108/EUM0000000005624.

Chitopanich, S. (2004). Positioning facility management. Facilities, 22(13): 364-372. doi: $10.1108 / 02632770410563086$.

Chung, Y.Y. (2008). A conceptual link among facilities management, strategic management and project management. Facilities, 26(13/14): 501-511. doi: $10.1108 / 02632770810914262$

Drion, B., Melissen, F. and Wood, R. (2012). Facilities management: Lost, or regained?. Facilities, 30(5): 254-261. doi: 10.1108/02632771211208512.

Ejovi, A. and Ebie, C.S (2013). Niger Delta: A critical appraisal of the amnesty programme and social political development in Nigeria. Research on Humanities and Social Sciences, 3(22): 130-137.

Featherstone, P. and Baldry, D. (2000). The value of the facilities management function in the UK NHS community health-care sector. Journal of Management in Medicine, 14(5/6): 326-338. doi: $10.1108 / 02689230010363052$.

Field, A. (2009). Discovering Statistics Using SPSS. 3rd Ed. London: Sage Publications.

Garengo, P., Biazzo, S., Simonetti, A. and Bernardi, G. (2005). Benchmarking on managerial practices: A tool for SMEs. The TQM Magazine, 17(5): 440-455. doi: $10.1108 / 09544780510615942$.

Hackett, S. and Parmanto, B. (2005). A longitudinal evaluation of accessibility: Higher education web sites. Internet Research, 15(3): 281-294. doi: $10.1108 / 10662240510602690$.

Halim, T., Muthusamy, K., Chia, S. and Lam, S. (2011). A systems approach in the evaluation and comparison of engineering services applied in facilities management. Facilities, 29(3/4): 114-132. doi: 10.1108/026327711111109252.

Hinks, J. and Hanson, H. (1998). Facilities management's profound strategic potential. Facilities Management World, June: 30-32.

Hinton, M., Francis, G. and Holloway, J. (2000). Best practice benchmarking in the UK. Benchmarking: An International Journal, 7(1): 52-61. doi: $10.1108 / 14635770010314954$. 
Ho, D., Chan, E., Wong, N. and Chan, M. (2000). Significant metrics for Facilities management in the Asia Pacific region. Facilities, 18(13/14): 545-555. doi: $10.1108 / 02632770010358088$.

Huq, F., Abbo, M.-H. and Huq, Z. (2008). Perceptions about benchmarking best practices among French managers: An exploratory survey. Benchmarking: An International Journal, 15(4): 382-401. doi: 10.1108/14635770810887212.

Jaques, M. and Povey, B. (2007). Assessing the changing role, attitudes and knowledge of UK business advisors to the benefits of benchmarking and benchmarking tools. Benchmarking: An International Journal, 13(52): 548565. doi: $10.1108 / 14635770710819308$.

Jensen, P.A. (2008). The origin and constitution of facilities management as an integrated corporate function. Facilities, 26(13/14): 490-500. doi: $10.1108 / 02632770810914253$.

Kincaid, D. (1994). Integrated facility management. Facilities, 12(8): 20-23. doi: $10.1108 / 02632779410062353$

Kok, H., Mobach, M. and Omta, O. (2011). The added value of facility management in the educational environment. Journal of Facilities Management, 9(4): 249-265. doi: 10.1108/14725961111170662.

Koleoso, H.A., Adewunmi, Y.A. and Adejumo, F. (2012). The practice of facilities management in Nigeria. Paper presented at the Euro Facility Management Conference. Copenhagen, Denmark, 23-25 May.

Koleoso, H.A., Omirin, M., Adewunmi, Y. and Babawale, G. (2013). Applicability of existing performance evaluation tools and concepts to the Nigerian facilities management practice. International Journal of Strategic Property Management, 17(4): 361-376. doi: 10.3846/1648715X.2013.861367.

Kyro, P. (2003). Revising the concept and forms of benchmarking. Benchmarking: An International Journal, 10(3): 210-25. doi: 10.1 108/14635770310477753.

Lai, H.K. and Yik, W.H. (2008). Benchmarking operation and maintenance costs of Iuxury hotels. Facilities. Journal of Facilities Management, 6(4): 279-289. doi: $10.1108 / 14725960810908145$.

Lindkvist, C. and Elmualim, A. (2010). Innovation in facilities management: From trajectories to ownership. Facilities, 28(9/10): 405-415. doi: $10.1108 / 02632771011057161$.

Madritsch, T. (2009). Best practice benchmarking in order to analyze operating costs in the health care sector. Journal of Facilities Management, 7(1): 6173. doi: $10.1108 / 14725960910929574$.

Magd, A.E. (2008). Understanding benchmarking in Egyptian organizations: An empirical analysis. Benchmarking: An International Journal, 15(6): 742-764. doi: $10.1108 / 14635770810915922$.

Magd, H. and Curry, A. (2003). Benchmarking: Achieving best value in publicsector organizations. Benchmarking: An International Journal, 10(3): 261286. doi: $10.1108 / 14635770310477780$.

Massheder, K. and Finch, E. (1998a). Benchmarking methodologies applied to UK facilities management. Facilities, 16(3/4): 99-106. doi: $10.1108 / 02632779810205639$.

. (1998b). Benchmarking metrics used in UK facilities management. Facilities, 16(5/6): 123-127. doi: 10.1108/02632779810211786.

Moriarty, J.P. and Smallman, C. (2009). En route to a theory of benchmarking. Benchmarking: An International Journal, 16(4): 484-503.

144/PENERBIT UNIVERSITI SAINS MALAYSIA 
Noor, M.N.M. and Pitt, M. (2009). A critical review on innovation in facilities management service delivery. Facilities, 27(5/6): 211-228. doi: $10.1108 / 02632770910944943$.

Ojo, P.K. (2002). Property management and facility management: Any difference?. Paper presented at the Continuing Professional Development Seminar on Facilities Management in Nigeria. Federal Palace Hotel, Lagos, Nigeria, 4 September. Lagos, Nigeria: Nigerian Institution of Estate Surveyor and Valuers.

Olaleye, A. (2000). A study of property portfolio management practice in Nigeria. MSc diss. Obafemi Awolowo University.

Róka-Madarász, L. (2010). Facility management benchmarking. Proceedings: 8th International Conference on Management, Enterprise and Benchmarking. Budapest, Hungary, 4-5 June, 171-181.

Spendolini, M.J. (1992). The Benchmarking Book. New York: Amacom Books.

Stoy, C. (2007). The application of a benchmarking concept. Facilities, 5(1): 9-21. doi: $10.1108 / 14725960710726319$.

Then, D. (1999). An integrated resource management view of facilities management. Facilities, 17(12/13): 462-469. doi: $10.1108 / 02632779910293451$.

Varcoe, B.J. (1996). Business-driven facilities benchmarking. Facilities, 14(3/4): 42 48. doi: $10.1108 / 02632779610112535$.

Waheed, Z. and Fernie, S. (2009). Knowledge based facilities management. Facilities, 27(7/8): 258-266. doi: 10.1108/02632770910956111.

Watson, G.H. (1993). Strategic Benchmarking: How to Rate Your Company's Performance against the World's Best. New York: John Wiley and Sons.

Wauters, B. (2005). The added value of facilities management: Benchmarking work process. Facilities, 23(3/4): 142-151. doi: 10.1108/02632770510578511.

Williams, B. (2003). Facilities Economics in the UK. Kent, UK: International Property and Facilities Information Ltd.

. (2000). An Introduction to Benchmarking Facilities and Justifying the Investment in Facilities. Kent, UK: International Property and Facilities Information Ltd.

Wong, Y.L. (2005). Facility management benchmarking: Measuring performances using multi attribute decision tools. PhD diss. The Hong Kong Polytechnic University. 